\title{
Comparing severity between Plasmodium falciparum malaria and sepsis
}

\author{
Ermelindo M Filipe ${ }^{1 *}$, Lina Antunes ${ }^{2}$, Esmael F Tomás ${ }^{1}$, Edna Viegas ${ }^{1}$, João Bernardo, Fortunato R Silva ${ }^{2}$ \\ From Parasite to Prevention: Advances in the understanding of malaria \\ Edinburgh, UK. 20-22 October 2010
}

\section{Introduction}

Malaria is the most important human parasitic disease, affecting about $40 \%$ worldwide population, most prevalent in tropical countries. Severe Plasmodium Falciparum Malaria is a cause of ICU in coming, appearing like in Sepsis with multi - organ failure, resulting in high mortality $10-50 \%$. Non-immune patient are most susceptible.

\section{Objectives}

Compare severity between severe Plasmodium falciparum Malaria and Sepsis.

\section{Method}

Severity between the 18 patients admitted with Severe Plamodium falciparum Malaria and the first 18 patients admitted with Sepsis in ICU -Sagrada Esperança Clinic during 2007 was compared concerning to age, sex, severity ICU scores (SOFA and APACHE II), organ failure and mortality. We also compared mortality between immune and non-immune patients for Malaria.

\section{Results}

See tables 1 and 2

Table 1 Comparing severity

\begin{tabular}{lccc}
\hline & Malaria $\mathbf{n}=\mathbf{1 8}$ & Sepsls $\mathbf{n = 1 8}$ & $P$ \\
\hline Age $(X \pm S D)$ & $39 \pm 12$ & $41 \pm 13.24$ & ns \\
Sex & M: $61 \%$ & M: $64 \%$ & \\
SOFA admission $(X)$ & 17 & 18 & ns \\
SOFA 3rd Day $(X)$ & 19 & 15 & ns \\
SOFA 7th Day $(X)$ & 17 & 9 & ns \\
Apache II & 10 & 12 & ns \\
Mortality & $27.8 \%$ & $47.4 \%$ & \\
\hline
\end{tabular}

${ }^{1}$ Sagrada Esperança Clinic ICU resident

Full list of author information is available at the end of the article
Table 2 Mortality under immunity for Malaria

\begin{tabular}{lcc}
\hline & Immune $\mathbf{n}=\mathbf{1 4}$ & Non-immune $\mathbf{n = 4}$ \\
\hline Mortality & $17 \%$ & $\mathbf{5 0 \%}$ \\
\hline
\end{tabular}

Table 3 Organ failure

\begin{tabular}{lcc}
\hline & Malaria $\mathbf{n = 1 8}$ & Sepsis $\mathbf{n = 1 8}$ \\
\hline Neurologic & $11.1 \%$ & $16.7 \%$ \\
Respiratory & $0 \%$ & $16.7 \%$ \\
Hematologic & $33.3 \%$ & $3 \%$ \\
Hepatic & $44.4 \%$ & $33.3 \%$ \\
Hemodynamic & $5.6 \%$ & $27.7 \%$ \\
Renal & $33 \%$ & $33.3 \%$ \\
\hline
\end{tabular}

\section{Conclusion}

There is no significant difference for severity comparing severe plasmodium falciparum malaria and Sepsis, there are similar organ failure rate.

Mortality among non-immune patients is high.

\section{Author details}

${ }^{1}$ Sagrada Esperança Clinic ICU resident. ${ }^{2}$ Sagrada Esperança Clinic ICU specialist.

Published: 20 October 2010

Reference

1. Snow RW, Guerra CA, Noor AM, Myint HY, Hay SI: The global distribuition of clinical episodes of Plasmodium Falciparum malaria. Nature 2005, 434:214-217.

doi:10.1186/1475-2875-9-S2-P10

Cite this article as: Filipe et al:: Comparing severity between

Plasmodium falciparum malaria and sepsis. Malaria Journal 2010

9(Suppl 2):P10. 